\title{
Rossini, músico do futuro. Nietzsche e Peter Gast na descoberta da grande saúde rossiniana*
}

\author{
Dorian Astor**
}

Resumo: o presente artigo tem o objetivo de refletir acerca das relações entre Nietzsche e o compositor italiano de ópera Gioachino Antonio Rossini. No intuito de traçar o desenvolvimento da influência do músico sobre o filósofo, o artigo realiza um apanhado e examina os textos de Nietzsche em que Rossini é citado. Ao longo do trabalho, tenta-se evidenciar que essa influência foi gradativa, mas de essencial importância nas vivências do filósofo. Como temática secundária, o artigo também traz algumas reflexões sobre a relação entre Wagner e Rossini. Palavras-chave: Rossini - Wagner - ópera - música.

"Rossini queria viver" Richard Wagner ${ }^{1}$

\section{Presença de Rossini}

Permita-me começar por uma observação pessoal: foram as antigas e duráveis afinidades que me conduziram a examinar o interesse de Nietzsche por Rossini. Desde a adolescência, minha paixão pela música tomou a aparência de Janus: Wagner e Rossini. Como se do ponto de vista das polaridades instintivas, toda a músi-

\footnotetext{
* Tradução de João Evangelista Tude de Melo Neto

**École polytechnique, França. Correio eletrônico: dorianastor@gmail.com.

1 WAGNER, R. Oper und Drama, in Gesammelte Schriften und Werke. Bde 3 \& 4 : Leipzig, 1907. Opéra et Drame, in Oeuvres en prose, trad. J.G. Prod'homme, t. IV. Éditions Delagave: Paris, 1910, p. 92.
} 
ca pudesse ser encontrada por trás de um ou de outro. As agitações gozosas suscitadas pelo primeiro contrastavam radicalmente com as virtudes terapêuticas do segundo. Eu sentia por conta própria que Rossini era não apenas um antípoda, mas também um antídoto. Assim, quando eu descobri Nietzsche um pouco mais tarde, não foi difícil atentar para sua "higiene" musical e, nela, encontrar, modestamente, um eco da minha. O papel de Wagner na obra e na vida de Nietzsche é massivo e central. $\mathrm{O}$ de Rossini é discreto, mas também significativo. Esse papel se inscreve com a mais estrita coerência na evolução do filósofo no que concerne a sua relação com Wagner, aos critérios de avaliação da música, às exigências dirigidas à arte, à crítica da modernidade artística e à possibilidade de uma cultura da "grande saúde". Em suma, eu desejava há muito tempo dar conta dessa relação entre Nietzsche e Rossini impelido por uma espécie de fidelidade a uma intuição de juventude.

O nome de Rossini aparece nos textos e nas cartas de Nietzsche apenas umas vinte vezes, e somente a partir de 1879, com uma primeira menção em Opiniões e sentenças diversas (VM/OS 171, KSA 2.450). Antes desta data, e apesar das observações críticas sobre a ópera italiana ligadas às reflexões que envolvem $O$ Nascimento da tragédia no início dos anos 1870 (elas concernem essencialmente ao nascimento da ópera ao gênero serio), nenhum compositor italiano do século XIX é mencionado, à exceção de Bellini, evocado apenas uma vez numa nota que faz menção à apreciação de Schopenhauer segundo a qual Norma encarnaria a perfeita realização da tragédia (Cf. Nachlass/FP ANO, 7 [127], KSA 7.186). ${ }^{2}$ Existe, todavia, uma única ocorrência precoce de Rossini nos textos de correspondência de Nietzsche. Trata-se de uma carta do filósofo a sua irmã Elisabeth, datada de 9 de julho de 1869 e redigida na Basileia:

2 O juízo de Schopenhauer sobre Norma aparece em $O$ mundo como vontade e representação, Suplemento ao livro III, cap. XXXVII (SCHOPENHAUER, A. Le Monde comme volonté et représentation. Trad. C. Sommer et all, Gallimard, 2009). 
Astor, D.

Enquanto isso, gostaria de lhe lembrar que, pelos binóculos de ópera, não se pode ver, além das margens do lago dos Quatro Cantões, uma realização melhor ou mais verdadeira que o Guillaume Tell de Rossini [...] Ai de mim! Que não posso te oferecer alguma outra representação de ópera em um lugar refratário com tais graças teatrais (Carta para Elisabeth, dia 9 de julho de 1869 KSB 3.26/27).

Se é verdade que a ação de Guilherme Tell situa-se à beira do lago dos Quatro-Cantões, a opera de Rossini apenas retoma o drama epônimo de Schiller, do qual Nietzsche era infinitamente mais familiar. Contudo, na ocasião dessa breve observação, é Rossini que o filósofo decide citar em vez de Schiller, sem dúvida porque a ele importa, sobretudo, sublinhar o pitoresco de uma paisagem que evoca as Theatergrazien da qual ele deplora a ausência nos teatros suíços, pouco inclinados às frivolidades italianas. ${ }^{3}$ Todavia Nietzsche conhece Rossini apenas por ouvir dizer e não dá nenhuma atenção particular ao compositor de ópera mais celebrado de seu tempo na Europa e mesmo na Rússia e na América. A notícia da morte do compositor, ocorrida alguns meses antes (13 de novembro 1868, em Paris), e que foi divulgada amplamente, não suscita nenhum comentário do jovem filólogo.

Quando Nietzsche retorna a Rossini, dez anos mais tarde, para evocá-lo em Opiniões e Sentenças diversas, ele ainda não conhece o compositor diretamente. É somente em 1881 que Nietzsche afirma ter assistido, sem dúvida pela primeira vez, a uma ópera de Rossini, Semiramide. Trata-se de uma breve menção em um cartão postal endereçado a Peter Gast (Heinrich Köselitz) enviada

3 De fato, Rossini, como também seus compatriotas tiveram dificuldades para penetrar na Suíça. Apesar de sua introdução tímida na Basiléia desde 1928, o repertório, até cerca de 1930, estará essencialmente centrado na ópera alemã e francesa. Guillaume Tell, contudo, composta em francês no estilo de uma "grande ópera francesa" e exaltando um herói nacional, não parece ter sido uma exceção. Cf. MUSCHTER, C. Musikleben in Basel : ein Führer durch die Vielfalt der Musikinstitutionen des Stadtkantons. GGG: Basel, 1982, p. 40; SCHIBLI, S. Musikstadt Basel: das Basler Musikleben im 20. Jahrhundert. Buchverlag der Basler Zeitung, 1999, p. 54.

150| Cad. Nietzsche, Guarulhos/Porto Seguro, v.38, n.1, janeiro/abril, 2017. 
de Gênova: "Eu estive - e digo isso com muita seriedade, por culpa sua - no teatro, onde eu assisti a Semiramide de Rossini e Giulietta e Romeo de Bellini (esta quatro vezes)." (Carta para Heinrich Köselitz, dia 6 de novembro de 1881 KSB 6.138-9). ${ }^{4}$ É, portanto, por conta dos conselhos de Gast que Nietzsche, que provavelmente não tomaria a iniciativa por si próprio, vai escutar esses compositores. Se dermos crédito à informação da carta, Nietzsche preferiu assistir a quatro representações sucessivas de Bellini, uma música mais elegíaca se comparada aos fastos solenes de Semiramide, última obra de Rossini para a Itália (Veneza, 1823), na qual brilhava o último fogo do gênero, agora apagado, da ópera séria. Mas, é ainda por estímulo de Gast que Nietzsche, entre 1881 e 1888, aprenderá a conhecer a obra lírica de Rossini. Em dezembro de 1888, descobrindo em Turim uma "opereta espanhola", ele escreve a Gast: "Uma vez que eu estou até o presente momento muito cultivado em Rossini e conheço já 8 óperas, eu tomei para comparação Cenerentola, minha preferida" (Carta para Heinrich Köselitz, dia 16 de dezembro de 1888 KSB 8.526-9). ${ }^{5}$ Dessa ópera, Nietzsche escutara um trecho desde 1883 e o havia apreciado sem saber de qual obra ele teria saído (Carta para Heinrich Köselitz, dia 17 de abril de 1883 KSB 6.359-361). Em oposição, a célebre Il Barbiere di Siviglia, escutada no final de fevereiro de 1882 em Gênova, não lhe havia ainda convencido, apesar de uma excelente qualidade de representação (Carta para Heinrich Köselitz, fim de fevereiro de 1882 KSB 6.172). Seus juízos acerca da ópera mais popular de Rossini serão emitidos com mais entusiasmo ao longo do tempo. Durante os anos 1880, Rossini aparece cada vez mais regularmente entre os nomes evocados por Nietzsche para ilustrar seu gosto cada vez mais marcado pela arte "clássica", isto é - no sentido goethia-

4 Pelo título Giulietta e Romeo, Nietzsche designa na verdade I Capuleti ed i Montecchi (Veneza, 1830)

5 A “opereta espanhola” em questão é uma zarzuela de Chueca e Valverde, La Gran Via. 
Astor, D.

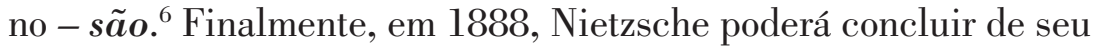
aprendizado que Rossini lhe é indispensável. ${ }^{7}$

Dessas menções factuais, pode-se concluir desde já que a descoberta de Rossini se inscreve na grande reviravolta do pensamento nietzschiano que aconteceu por volta de 1880, no seio da constelação formada notadamente pela demissão da Basileia e escolha pela Itália, pela ruptura com Wagner e aparição da segunda parte de Humano demasiado humano, pela leitura de Stendhal e, finalmente, pela intensificação da amizade com Peter Gast. Evocado aqui e acolá na literatura secundária, o interesse de Nietzsche por Rossini não foi objeto, que eu tenha conhecimento, de nenhum estudo detalhado. Lembra-se simplesmente que Nietzsche, que se considerava a partir de agora "com espírito suficiente para o Sul," (Nachlass/FP, 12 [181], KSA 9.607) coloca Rossini na lista dos compositores que ele irá, aos poucos, levantar contra Wagner. Além disso, Rossini entra, dentre outros melhores colocados do que ele, no processo de "mediterranização" da música reclamado pelo filósofo para fins terapêuticos, desconfiando que a música alemã não apenas corrompia o gosto, mas também comprometia a saúde (Cf. $J G B / B M$ 255, KSA 5.200/201). Nessa evolução bem conhecida, e que não é necessário lembrar aqui em detalhe, Rossini aparece, sem que jamais Nietzsche insista particularmente nele, ao lado de Händel, Mozart, Haydn, Mendelessohn, Chopin, Offenbach e evidentemente Bizet. Ninguém chamou atenção para o fato de que Rossini era o único italiano desse Panteão (por vezes, ao lado de Bellini), mesmo sabendo-se do caráter primordial da descoberta da Itália por Nietzsche. Pouco se falou, quando foi estudada a hoje já bem conhecida influência de Stendhal sobre Nietzsche, que a Vida de Rossini integrava suas leituras. No mesmo sentido, não foi observado o papel de Rossini na relação de Nietzsche com Gast. E,

6 No que diz respeito a essa questão, conferir o comentário de Patrick Wotling na sua edição de Gai Savoir, trad. P. Wotling, Flammarion, 2007, pp. 378 nota 67.

7 Cf. $N W / N W$, Intermezzo, KSA 6.420 e $\boldsymbol{E H} / \mathbf{E H}$, Por que sou tão inteligente, 7, KSA 6.274.

152| Cad. Nietzsche, Guarulhos/Porto Seguro, v.38, n.1, janeiro/abril, 2017. 
sobretudo, não foi dada a devida importância ao fato de que o próprio Wagner conferiu a Rossini um papel essencial no processo de elaboração de sua estética musical - e que Nietzsche sabia disso.

Wagner, juiz de Rossini.

Até 1881, portanto, Nietzsche é pouco familiarizado com Rossini. Por outro lado, ele conhece, desde 1868, a interpretação de Wagner acerca do compositor italiano, em Opera e drama. ${ }^{8}$ Nietzsche já havia lido este texto desde novembro, logo depois do primeiro encontro com o Wagner. Neste mesmo ano, a obra, um dos textos teóricos essenciais do período em Zurique do compositor no exílio (1851), acaba justamente de ser reeditada. Nietzsche declara a Rohde ter encontrado neste texto uma "legião de belas passagens" (Carta para Erwin Rohde, dia 25 de novembro de 1868, KSB 2.346) e aconselhará, em breve, a leitura a Gersdorff (Carta para Carl von Gersdorff, dia 4 de agosto de 1869, KSB 3.35-6). Nietzsche descobriu nesta obra a análise wagneriana da história da ópera, de sua decadência e de seu necessário ultrapassamento pelo "drama do futuro", o Musikdrama. Ora, na primeira parte do livro, "A ópera e a essência da música", Wagner dedica cerca de quinze páginas apenas a Rossini, e, de maneira rigorosa no segundo e no terceiro capítulo, ele confere ao compositor italiano um papel decisivo: o papel do derradeiro compositor verdadeiro de ópera. Isto é, Rossini seria o último sobressalto vital de um gênero condenado. Para Wagner, trata-se, na verdade, de justificar sua ruptura em relação às heranças musicais reais (o bel canto italiano, a grande ópera à francesa e a ópera romântica alemã) e substituílas por filiações idealizadas derivadas da tragédia grega, do drama shakespeariano e da sinfonia beethoviana. A música do drama musical

8 Cf. WAGNER, R. Oper und Drama, op. cit. 
Astor, D.

deveria nascer do único movimento de ação, inteiramente determinado pela intenção poética de se transformar num vasto continuum em desenvolvimento orgânico, segundo o modelo das sinfonias de Beethoven (da Nona em particular, que foi a primeira a fazer o canto brotar da matéria sinfônica). A decadência da ópera foi causada pelo abandono da intenção dramática como dinâmica exclusiva da gênese da música. Não é apenas o caso de que os compositores modernos tenham prostituído o gênero buscando atingir, por meio de efeitos musicais, o que apenas a inteligibilidade da poesia dramática podia suscitar. $\mathrm{O}$ problema fundamental é ainda mais grave, porque ele é inerente ao gênero: confunde-se, aqui, o fim (o drama) com meio (a música), as prioridades foram invertidas e perdeu-se a essência do drama tal como os gregos e Shakespeare nos haviam legado. A forma pura do efeito musical ou, mais precisamente, a negação da essência dramática da música, é a melodia, a melodia absoluta, isto é, de essência puramente instrumental. Quando esta se torna o princípio do canto, ela renega a essência da voz, que consiste em encarnar o Verbo e, portanto, o significado. No dia em que as explosões da voz humana rivalizaram com aquelas dos instrumentos, no momento em que as árias separadas foram concebidas como concertos para instrumento vocal, negligenciando tanto a poesia das palavras quanto o desenvolvimento da ação, o gênero já estava morto sem sabê-lo. Com a preciosidade metafórica que lhe é costumeira, Wagner compara a música dramática a uma flor e a melodia absoluta a seu simples perfume, e acusa "o homem ocioso e opulento" de ter desejado destilar artificialmente esse perfume para levá-lo sempre consigo, fazendo uso de flores secas para realizar esse intento. É nesse momento da análise que a figura de Rossini aparece no texto, não como poderíamos pensar, para acusá-lo de ter preservado o caráter mortífero da ópera, mas para demonstrar ter-lhe reconhecimento por ter compreendido que o gênero estava morto e

9 WAGNER, R. Oeuvres en prose, IV, pp. 89-98. 
de ter tentado, em vão, reanimá-lo. Wagner desenvolve a metáfora:

Ora, aquele que devolvia a esse perfume, tornado tão pouco natural, um corpo novo que, apesar de artificial, imitava pelo menos com a maior ilusão possível esse corpo natural que, da plenitude de sua natureza, havia espalhado esse perfume no ar, como o espírito de seu ser; este fabricante de flores artificiais extraordinariamente hábil, que fazia de veludo e de seda e pintava de cores enganadoras, umidificando seus cálices secos com essa essência de perfume, de tal modo que o odor delas parece quase aqueles das verdadeiras flores - esse grande artista foi Joachimo [sic] Rossini ${ }^{10}$

Assim que Rossini, guiado pela potência de seu instinto vital, compreende que a melodia era o único elemento ainda vivo na ópera, ele aposta tudo sobre ele. Ele traz a melodia em sua forma mais pura, aquela da "melodia simples, agradável aos ouvidos, absolutamente melódica, isto é, a melodia que era apenas melodia e nada além disso." E Wagner conclui por duas vezes: "Com Rossini, a história da ópera propriamente dita está terminada", e mais à frente: "certo é que, com Rossini, a ópera morreu"11.

É preciso desde já atentar para algumas problemáticas levantadas pela análise de Wagner e seu recurso à noção de melodia absoluta. Se confundem aqui, na maior das ambiguidades, diferentes problemas dos quais Wagner não é o inventor, mas que ele retoma de uma longa tradição de polêmicas em torno da ópera. Vemos em primeiro lugar a oposição entre música e verbo e a questão da hierarquia destes na essência do canto. Essa questão é tão velha quanto a invenção da monodia acompanhada da qual surgirá a ópera no início do século XVII, em torno das atividades teóricas e práticas da Carmerata fiorentina. Houve um intenso embate entre os que visavam tomar como princípio a máxima "prima le parole, $e$ poi la musica" e os que defendiam a proposição contrária. A essa oposição somou-se, no século XVIII, aquela acerca da melodia ou

10 Id. Ibid.

11 Id. Ibid. 
Astor, D.

da harmonia, isto é, a questão por meio da qual se perguntava se essência da música residia na sequência de acordes verticais determinada segundo regras matemáticas, da qual a melodia seria apenas uma consequência superficial, ou seja, a mera tradução horizontal sobre a linha do tempo; ou se, ao contrário, o fluxo melódico não seria a expressão primordial (natural e afetiva) a qual a harmonia vinha apenas sustentar e completar de forma subjacente. Essa polêmica implicava, na música vocal, o papel subsidiário ou estrutural do acompanhamento orquestral. A terceira luta por preeminência se deu entre a música e o teatro, uma vez que a ópera constituía-se como uma espécie de híbrido monstruoso desses dois gêneros de essências distintas. Enfim, o quarto conflito fez-se opor, por razões tanto políticas quanto estéticas, os estilos nacionais, principalmente o italiano e o francês. Desde que Mazarin trouxe à França compositores de ópera italianos, desde que o trânsfuga Lully tinha excluído seus antigos compatriotas para assegurar o monopólio de sua tragédia lírica à francesa, o nacionalismo musical seviciava com violência. É então numa enorme confusão teórica e histórica que se sucedem a querela dos lullistas e dos ramistas, a querela dos Buffons, aquela dos gluckistas e piccinistas etc. Durante um século, e até a tomada de consciência da necessidade de uma arte nacional no final do século XVIII, a Alemanha assistiu a esse conflito franco-italiano como espectadora ou como uma espécie de epígono dessa disputa.

No início do século XIX, essa guerra ainda não havia terminado e foi a glória de Rossini que, deste momento em diante, passou a concretizar o que estava em jogo na mesma confusão. Os italianos o achavam alemão demais: a orquestra e a harmonia deste que era apelidado de Tedeschino (o "alemãozinho" que, quando criança, se exercitava com as partituras de Mozart e de Haynd) foram consideradas demasiado prolixas, sacrificando a bela simplicidade de um Pergolèse ou de um Cimarosa. Os alemães do Sul eram germânicos o suficiente para reconhecer nele um novo Mozart e latinos 
o bastante para apreciar sua italianidade $;^{12}$ os alemães do Norte enxergaram nele o signo claro de uma decadência causada pela indolência meridional, com Carl Maria von Weber prevendo que "o siroco rossiniano soprando do sul" deixaria, muito em breve, o público extenuado. ${ }^{13} \mathrm{O}$ próprio Rossini, por meio de Guillaume Tell (Paris, 1829), havia tentado se reformular para atender às novas exigências do gosto francês. Wagner tinha, portanto, todo interesse em retomar essas críticas contra Rossini, pedra de toque inevitável na exposição de suas próprias reformas.

\section{Schopenhauer contra Wagner}

Ora, apenas três anos após a publicação de Opera e drama, Wagner estava perplexo com a descoberta de Schopenhauer, encontrando nele a visão de mundo que falava ao seu instinto metafísico. Ela se comunicava com o lado musical de Wagner, mas não a seu lado dramaturgo. Wagner se vê confrontado com o fato de que a posição de Schopenhauer estava em total contradição com sua própria concepção acerca do drama. De fato, $O$ mundo como vontade e representação afirmava o exato contrário de Ópera e drama: “... o texto [da ópera], por essa mesma razão, não deveria jamais abandonar sua posição subordinada para se colocar no centro, fazendo da música um simples meio de sua expressão, o que seria um grave erro e uma grande perversão". ${ }^{14}$ E, evidentemente, Schopenhauer não se absteve de trazer sua contribuição ao caso Rossini: "ninguém soube escapar deste erro melhor do que Rossini, uma vez que sua música fala com tanta pureza e evidencia sua linguagem PRÓ-

12 Cf. HANSLICK, E. "Rossini (Nekrologie)". In: Die moderne Oper. Kritiken und Studien: Berlin, 1875, pp. 101-122.

13 Cf. WEBER, C.M. von. "Kunstansichten”. In: Ausgewählte Schriften. K. Laux (Hrgs.): Leipzig, 1975, p. 53 sq.

14 SCHOPENHAUER, A. Le Monde comme volonté et représentation, III, §52, trad. C. Sommer et all, Gallimard, 2009, p. 510. 
Astor, D.

PRIA a tal ponto que ela não tem necessidade de palavras e que, executada com simples instrumentos, atinge seu efeito pleno". ${ }^{15}$

É verdade que Wagner, desde Ópera e drama, havia alimentado uma ambiguidade. Ele notadamente não foi capaz de clarificar, em seu conceito de drama, qual seria a diferença entre a materialidade do texto poético e o significado bastante extensivo que ele conferiria à noção de ação dramática. $\mathrm{O}$ compositor parecia dar prioridade à parole sobre a musica enquanto que, em realidade, ele entendia por "drama" a essência mesma de toda ação, isto é, seu desenvolvimento orgânico, do qual a música, mesmo pura, era portadora enquanto desenvolvimento de uma forma no tempo (assim, a sinfonia de Beethoven é, para Wagner, fundamentalmente dramática). É justamente em seu ensaio sobre Beethoven de 1870 que ele retornará a essa ambiguidade, explicando que os versos não têm o poder de determinar a música: "esse poder, apenas o drama o possui, e eu não me refiro ao poema dramático, mas ao drama que se desenrola sob nossos olhos, como reflexo tornado visível da música, onde a palavra e o discurso pertencem à ação e não ao pensamento poético". ${ }^{16}$ Em 1872, a releitura das provas tipográficas para uma nova reedição de Ópera e drama confirma-lhe mais uma vez o problema. Ele confidencia a Cosima: “eu sei que o que há lá dentro que não convém a Nietzsche, que é também o que colocou Schopenhauer contra mim, ${ }^{17}$ é o que eu disse acerca do Verbo; naquela época, eu não era ainda capaz de afirmar que foi a música que deu nascimento ao drama, apesar de, internamente, eu já sa-

15 SCHOPENHAUER, A.. op. Cit., p. 510. Cf. Igualmente Parerga et Paralipomena, §218.

16 WAGNER, R. Oeuvres en prose. Trad. J.G. Prod'homme, t. XI et . Éditions Delagave: Paris, 1923, p.121.

17 Que Schopenhauer tenha se "dirigido" contra ele consiste num exagero típico da personalidade de Wagner: o filósofo, que havia recebido do compositor o libreto do Ring em dezembro de 1854, tinha feito, distraidamente, uma observação a Franz Arnold Wille. O filósofo, no verão seguinte ao recebimento do libreto, afirmou que Wagner era genial como poeta, mas não como músico (cf. HÜBSCHER, A. "Schopenhauer und Wagner". In: Schopenhauer-Jahrbuch 37, 1956, p. 26). 
ber disso". ${ }^{18}$ Essa observação é de extrema importância: ela revela, por um lado, que Nietzsche, o qual tinha ajudado Wagner a reler as provas tipográficas, havia exprimido suas reservas acerca deste ponto; por outro lado, ela trai o embaraço duradouro de Wagner. Era essencial para ele reafirmar que a música pura encontrava sua verdadeira realização apenas por meio de sua elevação à música dramática, o drama sendo a essência mesma da música - enquanto expressão imediata da Vontade e porque ele pertence à essência do mundo como Vontade de ser trágico.

É por isso que o Nietzsche de $O$ nascimento da tragédia encontra-se ele mesmo pisando em falso. De fato, é "a partir do espírito de música" que o filósofo faz surgir a tragédia. Sua intuição profunda era que a música estava diretamente conectada ao mundo como Vontade ou, em sua nova linguagem, ao dionisíaco. E se o apolíneo foi uma noção essencial para Nietzsche, ela deve ter, antes de tudo, lhe servido para compreender a formação de uma civilização, sua plasticidade, sua produção de indivíduos, de instituições e de símbolos. É apenas por acréscimo que o apolíneo aparece para justificar o teatro e, ainda mais artificialmente, a ópera. Na verdade, teatro e ópera interessavam a Nietzsche muito menos que a música pura: fundamentalmente, para ele, como para Schopenhauer, ela era mais trágica do que a tragédia. Ora, de qualquer maneira que venha a requalificar o gênero a partir de suas reformas, Wagner era, no final das contas, apenas um compositor de ópera. Era necessário que Nietzsche, colocando nele - por motivos mais que musicais todas suas esperanças de reforma da cultura, pudesse, pela aliança do dionisíaco e do apolíneo na tragédia ática, justificar igualmente o drama musical wagneriano na sua pretensão ao renascimento do trágico na época moderna. Contudo, se tratava apenas de uma reforma musical, levantando os mesmos problemas e as mesmas questões sobre as quais Monteverdi e Gluck já haviam ponderado.

18 WAGNER, C. Journal, t. I (1869-1872), notation du 11 février 1872, Gallimard, 1977, p. 566. 
Astor, D.

Por muito tempo, Nietzsche resistiu a essa recontextualização, que foi inicialmente apenas hesitante, como se ele tivesse sido constrangido a se interessar pela ópera. Tradicionalmente, o gênero convidava a reflexões estruturalmente dualistas, que infligiam radicalmente o instinto filosófico de Nietzsche. Essa responsabilidade incumbia mais a Wagner do que a Schopenhauer. Em Genealogia da moral, Nietzsche acusará explicitamente o compositor de ter-se condenado, por sua conversão a Schopenhauer, a "uma contradição teórica entre a sua crença estética inicial e a posterior - a primeira expressa, por exemplo, em Ópera e drama, a última nos textos que publicou a partir de 1870" (GM/GM, III, 5, KSA 5.345), Quando se trata de música, Nietzsche permanece mais shopenhaueriano que wagneriano. Ora, ao livrar sua abordagem histórica e civilizacional do fardo de suas pesadas especulações metafísicas, Nietzsche se torna novamente capaz de investir o complexo sistema de oposições culturais que caracterizava as polêmicas acerca da história da ópera, acerca da essência dos gêneros artísticos e da hierarquia dos estilos nacionais. No momento em que ele dá um adeus definitivo a Wagner e à Alemanha, houve novamente um sentido em elaborar uma defesa consequente da ópera italiana. Essa defesa surgirá muito claramente na segunda parte de Humano demasiado humano. É também neste texto que aparece pela primeira vez uma menção publicada do nome de Rossini.

\section{Transvaloração da ópera}

Não seria possível analisar o despertar do interesse de Nietzsche por Rossini nos anos 1880 sem evocar, aqui, o papel desempenhado por Peter Gast. Os dois homens se conhecem pessoalmente desde 1875 e o primeiro encontro deles aconteceu por ocasião de uma discussão sobre a querela dos gluckistes e piccinistas cujo centenário era celebrado. No fim de abril de 1876, Köselitz convence Nietzsche a superar seus escrúpulos e a publicar Richard 
Wagner em Bayreuth cuja dimensão crítica permanecia mal dissimulada. A correspondência deles se intensifica e eles se aproximam ainda mais em 1880, quando decidem coabitar durante quatro meses (fevereiro-junho) em Riva e Veneza. A partir desse momento, Nietzsche terá uma experiência concreta da ópera italiana. Gast não apenas incita Nietzsche a frequentar os teatros italianos, mas ele próprio é um compositor italianizante, defensor da ópera buffa e autor de um Leão de Veneza (primeira versão, 1884) fortemente inspirada no Matrimonio segreto de Cimarosa. Gast é rossiniano, mesmo tendo confessado em março de 1881 que não o conhece plenamente e afirmado possuir apenas quatro partituras de ópera de Rossini. ${ }^{19}$ É Nietzsche que, por uma troca de gentilezas, recomenda a Gast a leitura de Vida de Rossini de Stendhal e envia-lhe um exemplar em 21 de março de 1881. Gast fica entusiasmado: "Pela extrema alegria que Stendhal me proporcionou, eu devo dizer-te ainda uma palavra repleta de reconhecimento (...) Eu estou impressionado com a acuidade de seu olhar sobre o horizonte histórico no seu livro sobre Rossini" ${ }^{20}$. Alguns dias mais tarde, ele decide até mesmo tomar, a partir de agora, Stendhal como guia, a fim de "dissipar as névoas propagadas há 50 anos por sobre a música". ${ }^{21}$ Quando, confrontado com as dificuldades de concepção de seu Leão de Veneza, ele sonha, em dezembro de 1881, com uma criação futura no Fenice de Veneza, a ideia que o emociona é que tanto Tancredi quanto Sigismondo de Rossini tinham sido criados

19 "Stendhal, um dia, chamou Rossini de o Voltaire da música! É um pouco exagerado, pelo menos até onde eu o conheço (eu possuo agora Le Barbier, Semiramis, Othelo, La Pie voleuse)". (Carta de Heinrich Köselitz, dia 31 de março de 1881, KGB III, 2.153).

20 (Carta de Heinrich Köselitz, dia 26 de março de 1881, KGB III, 2.151)

21 (Carta de Heinrich Köselitz, dia 31 de março de 1881, KGB III, 2.153). Parece que Gersdorff estava implicado no caso, uma vez que ele trabalha, no mesmo período, em uma tradução da Vida de Rossini de Stendhal (cf. Carta de Heinrich Köselitz, dias 15 e 22 abril de 1881 KGB III, $2.163 ; 167)$. Contudo, pelo que saibamos, não há correspondência escrita entre Nietzsche e Gersdorff acerca desse tema. 
nesse mesmo teatro setenta anos antes ${ }^{22}$. Até 1888, Gast é um dos raros interlocutores de Nietzsche acerca da ópera italiana e o único com o qual Nietzsche, em suas cartas, trata sobre Rossini.

Pelo lado de Peter Gast, as apreciações alemãs acerca da ópera poderão ser definitivamente varridas. A esse respeito, uma carta de Gast a Nietzsche, datada do final de 1880, é sem dúvida significativa, indo na contramão de tudo o que os preconceitos alemães (e franceses) tinham afirmado ao longo do século XIX:

Por diversas vezes, eu fui levado a me convencer da grande atenção que os italianos concedem às palavras que são cantadas com a música; enquanto que nós, alemães, somos muito menos preocupados com o texto, memorizamos a melodia e nos contentamos com isso. Os italianos sempre lamentaram, quando eu tocava para eles alguma coisa de Wagner ou de algum outro, que o texto, e, portanto, a compreensão correta da melodia, lhes fazia falta. Quando, como foi no meu caso, adquire-se um conhecimento mais exato das passagens de Schopenhauer sobre a melodia e sobre Rossini, é impossível deixar de se espantar com essa característica dos italianos, justamente porque a gente os imaginava absolutamente indiferentes ao que lhes é dado a conceber para além da música (Carta de Heinrich Köselitz, dia 08 de novembro de 1880, KGB III, 2.123).

Gast toma aqui o partido de Rousseau que, fervoroso partidário da ópera italiana contra a tragédia lírica francesa, considerava o idioma italiano como a única língua verdadeiramente adaptada ao canto. De fato, Gast não se apega simplesmente ao conteúdo de significação do texto cantado, mas às sonoridades e ao aspecto propriamente teatral dos sons. Nesta mesma carta, evocando Il Barbiere di Siviglia, ele considera que a língua italiana é por ela mesma o vetor do cômico próprio da ópera bufa: para ele, as inumeráveis repetições de palavras tais como "zitto là, zitto quà, zitto sù, zitto giù, zitti voi etc." perdem todo caráter cômico e se tornam absurdas se as cantamos traduzidas por "stille dort, stille hier etc.". 
Tais considerações influenciariam consideravelmente o julgamento de Nietzsche. Contudo, sobre a questão da relação entre palavras e música, ele não pode se desfazer de sua posição schopenhauriana. Por exemplo, no parágrafo 80 de $A$ gaia ciência ("Arte e natureza"), Nietzsche começa por defender a não naturalidade do teatro grego; contra Aristóteles, ele nega que a tragédia tenha tido por objetivo suscitar as paixões como terror e compaixão e estima que ela apenas reivindica o prazer do bem falar. Ele então compara o gosto grego pela bela linguagem à paixão italiana pelo belo canto, que dá ainda mais um passo em direção à não naturalidade: a ópera seria é indiferente, não apenas aos conteúdos de significação, mas também à materialidade das próprias palavras. É então Rossini que vem à mente de Nietzsche:

Talvez lhes tenha faltado apenas coragem para exprimir totalmente o seu menosprezo pela palavra: um pouco mais de atrevimento, e Rossini teria feito os personagens cantarem lá-lá-lá-lá do começo ao fim - e teria havido alguma razão nisso!" $(\boldsymbol{F W} / G C \text { 80, KSA 3.437 })^{23}$.

Era exatamente a opinião de Schopenhauer. E o parágrafo é concluído com um ataque direto contra Wagner: "Com frequência quis me parecer que seria necessário aprender de cor as palavras $\boldsymbol{e}$ a música de suas criações antes da apresentação; caso contrário - assim me pareceu - não se ouviria nem as palavras, nem a música sequer" $(F W / G C$ 80, KSA 3.437, tradução de PCS). Era igualmente a opinião de Gast.

É que, desde $O$ andarilho e sua sombra, Nietzsche tem a intenção de refutar o próprio conceito de música dramática, que ele considera como "uma absurdidade" (WS/AS 163, KSA 2.619); se Gluck teve razão contra Piccini, foi o caso de uma vitória pela força e não pela razão (WS/AS 164, KSA 2.620); forçar a música a falar uma linguagem dramática é "um pecado contra o espírito", uma extensão de efeito que pode apenas satisfazer às "almas embotadas"

23 Tradução de Paulo César de Souza. Doravante, indicado como PCS (N.T.). 
Astor, D.

(WS/AS 165, KSA 2.620). Ainda em 1887, a querela dos gluckistas com os piccinistas ocuparia as trocas epistolares entre Nietzsche e Gast. Nietzsche deslocou a oposição franco-italiana em direção de uma nova oposição fundamental dos estilos, para uma tipologia artística que ultrapassa ou suplanta as nacionalidades (afinal de contas, ele sublinha, o saxão Händel era "italiano” e o bávaro Gluck, "fancês"24. Em dezembro, ele lê uma obra de Arthur Pougin sobre Os verdadeiros criadores da ópera francesa, Perin e Cambert (1881) na qual ele descobre uma carta de Perin (1659) expondo em nove pontos as resistências dos franceses à opera italiana: "Essa carta, escreve ele a Gast, (...) é um fato capital para história da cultura ${ }^{25}$. Três dias depois, Gast dá a Nietzsche uma resposta nietzschiana:

A maioria do público italiano era piccinista, e eu creio que era assim em todo mundo: que significaria então o triunfo de Rossini? Os piccinistas (abstração feita de sua música habitualmente mais lisonjeira ao ouvido) me parecem ter a alma menor e, por isso, dotada de mais redondeza, mas eles são os verdadeiros ativos no mundo da ópera; perto deles, os outros são apenas abolicionistas, reativos. Veja o senhor, honrado professor, quanto os músicos já se precipitam sobre o seu método genealógico e dele se apropriam! (Carta de Heinrich Köselitz, dia 23 de dezembro de 1887 KGB III, 6.135)

Fazer da música, continua ele, o meio da expressão, como queria Wagner, é o signo de uma sujeição suspeita ao drama, uma negação da potência afirmativa da própria música. Nietzsche e Gast, ao curso de uma década de reflexões sobre a ópera, perceberam a transformação das querelas nacionais e estilísticas do século XVIII em oposições abusivamente metafísicas como o sintoma de uma superinvestida idealista, niilista e reativa do problema. Não é de se espantar, portanto, que, ao longo dessa mesma década, de Humano demasiado humano II a Ecce Homo, Nietzsche tenha transformado a questão da ópera em um problema histórico e o tenha inscrito, por

24 Carta para Heinrich Köselitz, dia 10 de novembro de 1887, KSB 8.190-2.

25 Carta para Heinrich Köselitz, dia 20 de dezembro de 1887 KSB 8.211-3.

164| Cad. Nietzsche, Guarulhos/Porto Seguro, v.38, n.1, janeiro/abril, 2017. 
fim, em uma fisiologia da decadência. Rossini, que encarnava costumeiramente a decadência da ópera, será beneficiado de maneira particular por essa reavaliação profunda.

\section{A nostalgia dos ideais partidos}

É preciso enfim ir ao parágrafo 171 de Opiniões e sentenças diversas, no qual aparece pela primeira vez o nome de Rossini. A ocorrência é a seguinte: "Apenas na música de Beethoven e de Rossini o século XVIII cantou derradeiramente, o século do entusiasmo, do ideais partidos e da felicidade fugaz" (VM/OS 171, KSA 2.453, tradução de PCS). A ideia geral do parágrafo, anunciada no título, é que a música é o "fruto tardio de toda cultura"; ela é mesmo às vezes o vestígio de um mundo antigo no seio de um mundo novo já realizado. Händel leva Lutero e a reforma ao acabamento, Mozart completa o século de Luiz XIV, de Racine e de Claude Lorrain. A música é por definição uma arte nostálgica, que tem a memória do passado e faz experimentar a volúpia das lembranças; ela também é a arte das transfigurações do já acontecido, arte sentimental e não inocente - num sentido schilleriano - em busca de uma natureza perdida e de ideais desaparecidos. "Toda música carregada de um sentido autêntico é um canto do cisne" (VM/OS 171, KSA 2.453, tradução de PCS). Dito de outra maneira, a música não é nem uma linguagem universal e intemporal (contra Schopenhauer) nem, sobretudo, uma arte do porvir (contra Wagner). ${ }^{26}$ A música - no sentido em que ela mede e transfigura o tempo que passa - contém em seu princípio mesmo esse ligeiro atraso inerente à memória, que capta sempre muito tarde o que está acontecendo agora. Assim, portanto, Beethoven e Rossini são ainda homens do século XVIII. Passemos rapidamente por essa interpretação original de Beethoven, habitualmente considerado como um músico

26 Cf. $N W / N W$, Uma música sem futuro, KSA 6.423/24, em que Nietzsche, quase uma década mais tarde, retoma literalmente o parágrafo 171 de Opiniões e sentenças diversas. 
revolucionário, vanguardista da escrita musical para todo século que estava por vir. Lembremos simplesmente que, apesar de toda sua admiração, Nietzsche ressaltará justamente em Beethoven o caráter de um romântico, a fadiga típica do romantismo e de seus "devaneios" [Schwärmereien] rousseauístas. ${ }^{27}$ Sublinhemos ainda que em seu Beethoven de 1870, Wagner tinha feito do compositor seu precursor, aquele que, levando a sinfonia ao seu último grau de expressão dramática, indicava o drama wagneriano como seu futuro - razão suficiente para orientar Beethoven ao passado.

Rossini, contudo, é outra coisa. Nietzsche nutre a seu respeito uma primeira intuição muito justa, e que o tempo irá confirmar. Em breve, de fato, ele poderá ler em Stendhal que Rossini era "o Voltaire da música";28 em 1888, Nietzsche ressalta um trecho de Rome, Naples e Florence de Stendhal no qual aparece uma anedota em que Stendhal pergunta a Rossini qual, dentre suas próprias óperas, ele preferia L'Italiana in Algeri ou Tancredi (as duas óperas que, em 1813, lançaram sua carreira internacional). $\mathrm{O}$ músico italiano teria respondido: "Il Matrimonio segreto", composta por Cimarosa vinte e um anos mais $\operatorname{cedo}^{29}$. Nietzsche descobriria, mais tarde em a Vida de Rossini, que o compositor mais célebre de seu tempo, no auge de sua glória, tinha decidido interromper brutalmente sua carreira em 1829, aos 37 anos de idade, depois de ter feito no século XIX a mais difícil concessão, que foi o Guillame Tell concebido para se tornar o modelo da grande ópera romântica à moda francesa. Rossini era o herdeiro consciente da ópera do século XVIII: tanto no gênero buffo quanto no serio, ele havia escrito para vozes formadas na grande escola napolitana que havia surgido por volta de 1650 e propagado por toda a Europa a arte deslumbrante dos castrati. Rossini, um jovem apressado, hedonista e carreirista, havia se tornado um grande burguês cético, melancólico

27 Cf. Por exemplo JGB/BM 245, KSA 5.187; Nachlass/FP 7 [7] KSA 12.284.

28 STENDHAL. Vie de Rossini. Paris : Gallimard, 1992, p. 58.

29 Cf. Carta para Heinrich Köselitz, dia 20 de junho de 1888, KSB 8.337-9

166| Cad. Nietzsche, Guarulhos/Porto Seguro, v.38, n.1, janeiro/abril, 2017. 
ao ponto da depressão. Ele havia passado pela experiência, em vida, de ter se transformado no vestígio monumental de uma época passada, ele havia mesmo acelerado sua obsolescência por meio de um silêncio voluntário. E é nesse sentido mesmo que Rossini foi um homem de seu tempo, ao mesmo tempo um moderno e um inatual.

Wagner, revolucionário no exílio, tinha escrito em Ópera e drama que Rossini era no fundo um reacionário, enquanto que Gluck e seus sucessores tinham sido revolucionários, e acrescenta: "Da mesma maneira que Metternich não podia, de forma legítima, compreender o Estado senão que sob o regime de uma monarquia absoluta, Rossini, não com menos lógica, concebia a ópera apenas sob o signo da melodia absoluta". ${ }^{30}$ Deixando de lado os jogos de palavras, Wagner retoma aqui uma opinião corrente entre os liberais alemães, opinião que ele encontra sem dúvida em Heinrich Heine. Este havia escrito em suas Cartas sobre a cena francesa (1837) o seguinte:

A música de Rossini é mais adaptada [do que a de Meyerbeer] à época da Restauração na qual, depois de grandes lutas e grandes decepções, o sentido dos grandes interesses gerais devia, nesses homens entediados e indiferentes, passar para segundo plano e ceder lugar aos sentimentos da individualidade e de seus direitos legítimos. ${ }^{31}$

Nós veremos que Peter Gast também percebe esse sentimento de individualidade em Rossini. Por ora, notemos que Nietzsche reconhece em Rossini a marca de uma historicidade radical, o signo de uma "cultura bem determinada, delimitada no tempo e no espaço" (VM/OS 171, KSA 2.453, tradução de PCS) Ora, ele não a inventou: é no próprio Wagner que ele encontra essa ideia, quase literalmente. Em Uma lembrança de Rossini, um artigo de 1868, o compositor tinha escrito:

Rossini será bem avaliado conforme seu verdadeiro valor apenas

30 WAGNER, R. Opéra et drame, p. 97.

31 HEINE. H. Über die französische Bühne. In: Werke und Briefe. Berlin: H. Kaufmann (Hrsg.), Bd 6, 1962, p. 65. 
Astor, D.

quando tivermos ensaiado, de uma maneira inteligente, uma história da civilização de nosso século partindo de seu início até alcançar nossos dias; nesse trabalho, em vez de ceder à tendência em voga, que atribui à civilização deste século o caráter completamente exclusivo de um progresso universalmente florescente, dever-se-ia, enfim, simplesmente não perder de vista a real decadência de uma civilização anterior, delicada de espírito; se esse caráter de nosso tempo estivesse delimitado com exatidão, o verdadeiro lugar que Rossini deve ocupar de direito, sem dúvida, não deixaria de lhe ser atribuído com a mesma exatidão. E esse lugar não seria de maneira alguma desprezível; de fato, na mesma proporção em que Palestrina, Bach e Mozart, pertencem a seus respectivos tempos, Rossini pertence também ao seu. ${ }^{32}$

Mesmo a comparação com Palestrina está presente, a qual Nietzsche retoma no seu parágrafo 171 (“a música de Palestrina seria totalmente inacessível a um grego, e, por sua vez - o que ouviria Palestrina na música de Rossini?") Mas eis que, enquanto Wagner sublinhava, seguindo os passos de Heine, a dimensão reacionária de um Rossini exemplar da época da Restauração europeia, subentendendo que ele próprio, ao contrário, estaria do lado dos revolucionários de 1848, Nietzsche retoma a ideia de que a música do século XIX é reacionária - mas é Wagner que ele acusa:

O espírito de sua música [...] empreende, no sentido da reação, a última campanha contra o espírito da filosofia dos iluministas, cujo sopro, originado do último século, penetrou neste, tanto contra as ideias supranacionais da utopia revolucionária francesa como também contra aquela do realismo anglo-americano na refundição do Estado e da sociedade (VM/OS 171, KSA 2.453, tradução de PCS).

Há, então, duas maneiras se ser nostálgico para um músico do século XIX: seja "clássico", como Rossini, cantando a lembrança "dos ideais partidos", afirmando a não-naturalidade da arte e a felicidade fugaz da individualidade superior; seja "romântico", movido

32 WAGnER, R. Souvenirs, "Un Souvenir de Rossini. Trad. de C. Benoît, G. Charpentier et Cie, éditeurs, 1884. 
por uma nostalgia em relação a uma natureza desaparecida e sobretudo pelo ressentimento de ter perdido várias revoluções. $\mathrm{O}$ primeiro se conforma no silêncio, o segundo anuncia com grande barulho uma arte regenerada. $\mathrm{O}$ reacionário não é aquele que se imagina.

Mas é preciso ir mais longe na compreensão do que pode significar, para Nietzsche, a nostalgia exprimida fundamentalmente pela música. Sua análise se investe de uma dimensão pessoal que aparecerá por surpresa, como uma repentina confissão pessoal, no parágrafo 168 do Andarilho e sua sombra. Nesse parágrafo, intitulado "Sentimentalidade na música", ele fala sobre os "tão singelos melismas de óperas italianas" (WS/AS 168, KSA 2.622, tradução de PCS), sobre essas melodias que são apenas melodias. Nietzsche explica aí que elas são "a própria alma da música," que é preciso "resolver tal enigma." Ele remete então à infância, à idade em que se descobre tudo pela primeira vez:

Naquele [época] então - talvez por volta dos nove anos de idade ouvimos a primeira música: foi aquela que entendemos primeiramente, a mais singela e infantil, portanto; não mais que um prosseguimento da canção da babá ou da melodia de um realejo. [...] É a esses primeiros arrebatamentos musicais - os mais fortes de nossa vida - que se conecta a nossa sensibilidade, quando ouvimos aqueles melismas italianos: a felicidade infantil e a perda da infância, o sentimento do irrecuperável como a posse mais preciosa (WS/AS 168, KSA 2.622, tradução de PCS).

O encanto de toda música começa a operar quando ela começa a "falar a linguagem de nosso próprio passado". Aí está sem dúvida uma das razões pelas quais Nietzsche encontrará em Rossini as marcas definitivas dos ideais partidos e das felicidades fugazes.

\section{Rossini contra Wagner}

Quais foram os ideais e as felicidades de Rossini? Por uma feliz ironia da História, acontece que o italiano, cujo pudor o le- 
vou a expressar-se apenas de forma bastante rara sobre sua própria arte, se abriu sobre o assunto justamente a... Wagner em pessoa! No dia 18 de março de 1860, os dois homens, então vizinhos em Paris, se encontram e têm a possibilidade de confrontar suas concepções acerca da música. Esse encontro está documentado por dois textos importantes: um, do próprio Wagner, é um artigo redigido por ocasião da morte de Rossini, publicado no dia 6 de dezembro de 1868 em Leipzig e imediatamente traduzido para o francês para Le Ménestrel (janeiro de 1869), com o título de Uma lembrança de Rossini. ${ }^{33} \mathrm{O}$ outro é o testemunho de um amigo de Rossini, Edmond Michotte, que estava presente no encontro dos dois artistas e o registrou, sob a forma de uma transcrição, em Lembranças pessoais, A visita de Richard Wagner a Rossini, publicado pelo livreiro Fischbacher em Paris em 1906. O intercâmbio foi extremamente cordial e é preciso reconhecer que a partir desse encontro, os textos de Wagner sobre Rossini serão marcados por uma admiração mais franca do que em Ópera e drama (apesar de que mesmo aí ela já tenha sido perceptível). Após as cordialidades usuais, o relato de algumas lembranças e de uma conversa rápida sobre os grandes compositores, Rossini entra diretamente no assunto e pergunta a Wagner sobre quais foram os pontos de partida para sua vontade de reforma da ópera. Este explica que sua preocupação inicial tinha sido a dimensão poética e dramática da ópera a fim de arrancá-la da rotina e das convenções do gênero, especialmente da forma de ar de bravura, mortal para a condução do drama. Rossini então responde nos seguintes termos:

Seu argumento [...] é sem objeção, ao considerar apenas o desenvolvimento racional, rápido e regular da ação dramática. Só que, como manter, dentro da aliança da concepção literária com a forma musical (que é apenas convenção), esta independência que a primeira reclama? Você disse a palavra! Uma vez que é preciso permanecer no espírito da lógica

33 WAGNER, Souvenirs, “Un Souvenir de Rossini». pp. 233-246. 
absoluta, é natural que não se cante fazendo um discurso; o homem colérico, o conspirador, o ciumento não cantam! (descontraidamente): uma exceção talvez sejam os apaixonados que se pode admitir fazê-los cantar arrulhando... Ainda mais problemático: encaminha-se para morte cantando? Portanto, convenção a ópera é de ponta a ponta. E a própria instrumentação?... Quem então, numa orquestra desbridada, poderia precisar a diferença de descrição entre uma tempestade, um motim, um incêndio?... convenções novamente! ${ }^{34}$

Para Rossini, a música não imita nada, ela não possui os meios para imitar a verdade, o real, ou a ação; por outro lado, justamente por essa deficiência, ela se eleva acima do mundo real em direção de um mundo ideal, cuja essência é a expressão pura. Em outro testemunho mais antigo, Zanolini, um amigo de Rossini, relata uma discussão acerca desse assunto, durante a qual o mestre havia qualificado a música como "arte tutta ideale e espressiva". 35 A música persegue "um fim mais elevado, mais profundo, mais abstrato que a palavra," esta se atém às particularidades concretas dos sentimentos; a música, ao contrário, exprime a afetividade em geral. Stendhal faz eco a essa concepção quando escreve: “A única coisa real na música é o estado no qual ela deixa a alma, e eu estaria de acordo com os moralistas ao dizer que este estado dispõe fortemente ao devaneio e às paixões ternas" ${ }^{36}$ Compreende-se por que a pretensa expressividade da declamação wagneriana e, igualmente, o conteúdo de significação concreto do que restava da melodia sob a forma do leitmotiv, deviam, aos olhos de Rossini, encarnar o fracasso da idealidade da ópera. Seguir servilmente a inflexão da ação dramática até no comentário de seus mais ínfimos detalhes significa se dedicar a uma extinção de toda forma, mas também, para dizê-lo em termos nietzschianos,

34 MICHOTTE, E. Souvenirs personnels. La Visite de Richard Wagner à Rossini. Fischbacher, 1906, p. 37.

35 ZANOLINI, A. Gioacchino Rossini, Zanichelli: Bologne, 1875. "Una passeggiata con G. Rossini (1836)" é retomado em: ROGNONI, L. Gioacchino Rossini, nuova edizione riveduta e aggiornata, Einaudi, 1977, pp. 375-381.

36 STHENDHAL. Vie de Rossini, p. 50. 
Astor, D.

consiste em se condenar a um esgotamento fisiológico de um caos pulsional. E em uma explicação que soa como uma profissão de fé clássica, Rossini adverte Wagner:

Do ponto de vista da arte pura, estes são, sem dúvida, pontos de vista bem amplos, perspectivas sedutoras. Mas do ponto de vista da forma musical, em particular, é a consequência fatal da melopeia declamatória: a oração fúnebre da melodia. Senão como aliar a notação expressiva de cada sílaba da linguagem, por assim dizer, à forma melódica, da qual um ritmo preciso e a concordância simétrica, de membros que a constituem, devem estabelecer a fisionomia ${ }^{37}$

A melodia não é o perfume artificial de flores ressecadas, ela é um corpo determinado por sua forma, por sua organicidade, por sua ritmicidade próprias. Por esta razão, ela é portadora de expressão apenas quando firme e poderosamente estruturada. Nós tocamos aqui num ponto central da estética rossiniana; que Nietzsche, indo além das nostalgias de infância e da simplicidade suposta do melisma italiano, vai pouco a pouco compreender e experimentar ele próprio como ouvinte.

\section{Novo Orfeu}

No outono de 1884, enquanto trabalha na quarta parte de Zaratustra, Nietzsche redige uma série de fragmentos poéticos em que se misturam a palavra hínica de seu personagem e uma voz mais pessoal, sob a forma de dedicatórias a Schopenhauer, a Spinoza, a Wagner, aos falsos amigos, aos alemães, aos criadores, aos espíritos livres etc. ${ }^{38}$ Dentre esses fragmentos, um poema sem título foi provavelmente dedicado a Peter Gast. Vejamos as duas primeiras estrofes:

37 MICHOTTE, E. Souvenirs personnels. Op. Cit., p. 41

38 Trata-se do caderno 28 de Nachlass/FP, KSA 11.302. 
Veja que a partir de agora tudo me foi dado

A águia de minha esperança descobriu

Uma Grécia pura e nova

Salvação de audição e dos sentidos -

Deixando a sufocante cacofonia alemã

Para Mozart, Rossini e Chopin

Eu vejo teu navio, Orfeu alemão

A mudar de bordo em direção a nuvens gregas

(Nachlass/FP, 28 [10], KSA 11.302).

Nós não discutiremos aqui a cegueira de Nietzsche em relação ao talento musical de Peter Gast. Ele sempre acreditou em seu talento e se engajou publicamente por seu amigo, tentando recomendá-lo a produtores sempre que podia. No outubro de 1885 , Nietzsche escreve uma carta a Ernst Schuch, então diretor de ópera de Dresden, e elogia Gast nestes termos: "Aqui o ponto de ouro da reconciliação é excedido, aquele que passa por Mozart, Rossini e Wagner, e vai além deles - aqui se casam novamente a beleza meridional, a graça do coração, o céu claro, uma alegria de espírito descontraído com a profundeza nórdica, o fundo da erudição e da interioridade alemães" (Carta para Ernst Schuch, do começo de outubro de 1885, KSB 7.95-96). Essas não são palavras vãs, e as notas pessoais de Nietzsche provam que ele é sincero, como no rascunho poético acima ou no fragmento seguinte, no qual ele escreve a propósito de Gast: "Eu vejo aqui um músico que fala a língua de Rossini e de Mozart como sua língua materna, essa língua popular da música, terna e louca, alternadamente muito suave e muito barulhenta" (Nachlass/FP, 6 [22] KSA 12.239). Compreende-se os motivos desse entusiasmo excessivo: por um lado, é a Gast que Nietzsche deve sua descoberta da música italiana, é graças a ele que o filósofo pôde desenvolver suas reflexões e moldar seu gosto em matéria musical, e era sem dúvida inevitável que ele fizesse a confusão, entre os tesouros que seu amigo havia lhe ofertado, isto é, entre aqueles que não estavam a sua mão e aqueles que ele 
Astor, D.

próprio tinha criado, a partir da imitação dos primeiros. Por outro lado, Nietzsche sonhou sem dúvida com uma relação inversamente simétrica daquela que ele havia vivido com Wagner: outrora filósofo turiferário de um grande músico, ele esperava talvez encontrar um músico que encarnasse musicalmente sua própria filosofia. Nietzsche tinha necessidade de aliados e nutriu por Gast grandes esperanças, como testemunha esse poema dedicatório. É supérfluo lembrar que Nietzsche, aqui, está ligado à longa tradição filohelenista da Alemanha de Goethe, de Schiller ou de Hölderlin: no seio de uma civilização alemã que viveu como semibárbara, a via da elevação passará pela necessidade de se tornar um pouco grego. Mas também se trata da retomada de um topos retórico amplamente difundido nos séculos XVII e XVIII, que consistia em comparar a Orfeu um compositor nacional capaz de sintetizar diferentes estilos europeus e alargar assim o horizonte estético de seu país de origem (assim Purcell foi o Orfeu britânico e Telemann um Orfeu alemão). ${ }^{39}$ Ser Orfeu significava reatar com as origens gregas de uma arte poética fazendo-se um com o canto, mas também, portanto, reatar com as origens italianas da ópera: não foi à toa que Monteverdi escolheu este mito quando ele ofereceu à Itália sua primeira obra-prima, O Orfeu (1607). Nada menos que isso é esperado do compositor e amigo Peter Gast (mas também dele mesmo) neste poema. A Grécia musical de Nietzsche é doravante "Mozart, Rossini, e Chopin".

Nietzsche quase sempre associa Mozart ao Meio-dia [Midi] e à alegria de espírito [Heiterkeit], a leveza que mistura a felicidade e a melancolia: "o espírito de Mozart, o jovial, terno, entusiasta, enamorado espírito de Mozart, que por felicidade não era alemão e cuja seriedade é bondosa e dourada, não a seriedade de um filisteu alemão" (NW/NW, Wagner como perigo, 2, KSA 6.423, tradução de

39 Quando do seu encontro com Wagner, com sua ironia legendária, Rossini recebe Wagner com esta exclamação: "Ah! Senhor Wagner, como um novo Orfeu, não temeis de transpor esse limite perigoso" (E. MICHOTTE. Souvenirs personnels; la Visite de Richard Wagner à Rossini, p. 19). 
PCS) ${ }^{40}$ Chopin (cuja música para piano havia sido bastante tocada por Nietzsche e Gast durante sua convivência em Veneza), polonês tal como o próprio Nietzsche sonhava em sê-lo, é igualmente uma das grandes paixões do filósofo: antídoto para o romantismo sem forma de Schumann, Chopin encarna o domínio perfeito da complexidade desenvolvida a partir de células simples (cf. Nachlass/ $F P, 28$ [47], KSA 8.510) (aquelas das melodias da infância?), "principesca nobreza da convenção" (WS/AS 159, KSA 2. 618), "o ardor e a densidade meridional do sentimento" (Nachlass/FP, 21 [2], KSA 9.681).

\section{Boa consciência animal}

De acordo com o que dissemos, vê-se muito bem o que aproxima quase sempre Rossini de Mozart e de Chopin. Contudo, trata-se de uma característica que Nietzsche nunca atribuiu nem a Mozart nem a Chopin quando fala apenas deles: é a dimensão popular, "muito barulhenta" e "louca". Stendhal, se referindo à L'Italiana in Algeri, não havia escrito que ela era apenas "uma loucura organizada e completa?"41 Rossini, no primeiro final de A Italiana, em vez de la-la-la, como almejava Nietzsche, não havia tido efetivamente essa "impudência" de fazer cantar seus personagens justamente sobre din, din, bum, bum, cra cra, tac, tac, puras onomatopeias evocando a confusão cerebral causada por um excesso de quiproquós? (o que, aliás, é testemunho de um certo gênio da ação dramática...)? Rossini teve, de fato, essa louca insolência que flertava sabiamente com a vulgaridade, o gosto pelo tumulto (os famosos crescendi) e pelo delírio. Ora, essa "vulgaridade" nunca incomodou Nietzsche, como reconhece o parágrafo 77 de $A$ Gaia ciência:

O elemento vulgar em tudo o que agrada no Sul da Europa - seja a ópera italiana (a de Rossini e de Bellini, por exemplo) ou o romance espanhol

40 Cf. também WS/AS 154 e 165, KSA 2.442/445 M/A 218, KSA 3.193; JGB/BM 245, KSA 5.187. 41 STENDHAL. Vie de Rossini, p. 108. 
Astor, D.

[...] não me escapa, mas também não me ofende, assim como a vulgaridade que encontramos num passeio por Pompeia e, no fundo, até na leitura de qualquer livro antigo: de onde vem isso? Seria que a vergonha está ausente, e que tudo o que aí é vulgar se apresenta com certeza e segurança de si de qualquer coisa nobre, passional e graciosa na mesma espécie de música ou romance? (FW/GC 77, KSA. Tradução de PCS 3.432).

O que é popular é o direito à vulgaridade ao disfarce, "a boa consciência do disfarce" (FW/GC $77 \mathrm{KSA} 3.432 / 433)$, que é uma consciência animal. Esse animal com boa consciência, que dá título ao parágrafo, é aquele que fascina Nietzsche quando ele descobriu Nápoles, por ocasião de sua viagem de 1877 e depois nos textos de Stendhal: esse catolicismo popular e fundamentalmente pagão que ignora a culpabilidade e, ao mesmo tempo, é alegre na vingança; essa fé exuberante dos lazzaroni "que possuem como lei apenas o temor ao deus São Januário" e "a sensação presente". ${ }^{42}$ É esse espírito napolitano, também encontrado em Gênova, que Nietzsche evocará na quarta parte de A Gaia Ciência, sob o título de "Sanctus Januarius". Ora, em fevereiro de 1882 (logo após esse famoso janeiro genovês, miraculosamente ensolarado e inspirador), Nietzsche lê, da própria pluma de Peter Gast, a descrição dessa característica a respeito de Rossini. Gast havia acabado de escutar Il Barbiere di Siviglia e escreve:

Eu encontro em Rossini, e sobretudo no "Barbeiro", uma genialidade sem limites - infelizmente ligada a toda preguiça do Italiano. Em lugar nenhum, nem mesmo em Mozart, eu encontrei uma espontaneidade como em Rossini (o Alemão não possui expressão correspondente, - na verdade porque ele não sabe muita coisa acerca da espontaneidade). No "Barbeiro", eu não sinto nada que lembre um esforço, - nos outros, isso é percebido com frequência (em Chopin, por exemplo, não é raro) [...] Quantas coisas em Rossini são tornadas coloridas e cintilantes, que parecem o mármore frio em Mozart e Cimarosa! E esses crescendi rossinianos, durantes os quais

42 STENDHAL. Rome, Naples et Florence. In: Voyages en Italie. Paris: Gallimard, "Bibliothèque de la Pléiade", 1973, p. 364. 
a orquestra parece começar a ferver e borbulhar (por exemplo, a entrada de Fígaro), eu o sinto agora como o barulho mais agradável ao meus ouvidos. Tomar um sentimento a sério - Rossini jamais pôde fazê-lo [...] Ele é tão ruim ou tão bom que ele não dá nem mesmo má consciência (Carta de Heinrich Köselitz, dia 26 de fevereiro de 1882, KGB III, 2.229). ${ }^{43}$

Aí está o que é próprio a Rossini e que nem Mozar nem Cimarosa possuem. Nem mesmo Belini, que Nietzsche cita voluntariamente ao lado de Rossini e no qual ele reconhece a origem popular de suas mais belas melodias (Carta para Heinrich Köselitz, dia 24 de março de 1883, KSB 6.349-51); ${ }^{44}$ Gast, menos indulgente, sente em Bellini "alguma coisa como a transpiração dos trabalhadores nessa música; ela deve provavelmente ter alguma ligação com as aspirações socialistas e as realizações desse século". ${ }^{45}$ Mais nietzschiano que Nietzsche, Gast é ainda mais sensível do que ele no que se refere à dimensão aristocrática de Rossini, isto é, a respeito da potência apolínea de individuação que ele encarna. Assim, ele se junta ao julgamento de Heine ou de Wagner sobre "o individualismo" rossiniano, que estes qualificam de reacionário, mas que Gast tem em alta estima, como signo de nobreza. Essa exaltação da individualidade, Gast experimenta justamente quando ele observa os grandes cantores italianos rivalizando virtuosidade com ares de

43 Reconhece-se a influência de Stendhal, que escrevia em sua Vida de Rossini, com acentos nietzschianos: "O novo compositor faz jorrar abundantemente as novas ideias; ora ele tem sucesso, frequentemente ele perde seu objeto. Tudo está amontoado, tudo está na desordem, tudo está negligenciado; é a profusão e a despreocupação da riqueza sem limites" (p. 57).

44 Nietzsche repensou sobre Bellini no momento de sua estada em Messina: o compositor era originário da Catânia, bem próximo.

45 (Carta de Heinrich Köselitz, dia 29 de março de 1883, KGB III, 2.356). Notemos aqui que nem Gast nem Nietzsche mencionam nem uma só vez o nome de Donizetti. Quanto ao muito popular Verdi, ele aparece apenas uma vez em uma anotação de Nietzsche: ele recopia uma fórmula da célebre cantora lírica Giuditta Pasta, que, “contra a opinião de Mérrimé”, declara: “desde Rossini não se fez mais ópera que tivesse uma unidade e onde todas se sustentam. 0 que faz Verdi, por exemplo, parece uma roupa de Arlequim" (Nachlass/FP, 26 [419], KSA 11.263). Essa roupa de Arlequim nos leva a pensar no traje variegado e ridículo com o qual Nietzsche veste regularmente o homem moderno. 
bravura, numa suspensão espetacular da ilusão teatral para expor apenas a pura alegria das performances sobrenaturais do corpo versado numa técnica de tirar o fôlego:

O cantor italiano quer e deve se mostrar como cantor, e não como personagem dramático integrado à ação [...] Até o final do último século não havia coro na ópera italiana, porque o italiano almeja a bravura pessoal, e então por exemplo o canto com coloraturas. É por essa razão mesma que não existiu um verdadeiro drama na Itália...talvez por conta dessa falta de sentimento gregário que se tornou sensível nos centros onde se desenvolveu o Renascimento [...] 0 mesmo principium individuationis, para exprimi-lo assim, atravessou verdadeiramente os cantores de ópera (Carta de Heinrich Köselitz, dia 23 de dezembro de 1887, KGB III,6.135).

Essa análise central está na contracorrente de todas as críticas endereçadas, desde o século XVIII, à ópera seria italiana. Assim como também vai na direção contrária de todas exigências de reformas do gênero: de Gluck a Wagner, os reformadores não cessavam de queixar-se da excessiva importância dada aos intérpretes exibicionistas que se serviam da obra para satisfazer suas vaidades no lugar de colocarem-se a serviço dela. Mesmo Rossini se queixava! ${ }^{46}$ Mas ainda mais fundamentalmente, Peter Gast traduz aqui, mais uma vez, seu gosto musical em termos nietzschianos, e para Nietzsche. Do mesmo modo que ele fez quando convocou o método genealógico para analisar a querela entre gluckistas e piccinistas (qualificando-os de ativos e reativos); do mesmo modo que ele acusava a ópera do século XIX de participar da moral de rebanho, ele faz aparecer nessa carta o princípio apolíneo que preside a arte do canto do qual Rossini foi o último representante.

46 Ele se abre, por sinal, para Wagner: "Entre outras coisas, o senhor acaba de fazer alusão à aria di bravura. A quem o senhor se dirige? Esse era meu pesadelo. Contentar simultaneamente à primma donna, il primo tenore, il primo basso!... Havia alguns desses palhaços - sem jamais esquecer suas terríveis versões femininas - que ousavam contar o número de compassos de seus ares somente para depois vir me dizer que não cantariam, pois um de seus colegas tinha um ar com tantas medidas a mais, sem contar o maior número de trilos, gruppetti..." (MICHOTTE, E. Souvenirs personnels; la Visite de Richard Wagner à Rossini, p. 36). 
O apolíneo, o aristocrático e o clássico traduzem aqui apenas um só e mesmo fenômeno que, de A Gaia ciência a Ecce Homo, será central em Nietzsche: a grande saúde. E ajustando suas últimas contas com a doença Wagner e com a modernidade, é Rossini que Nietzsche evoca no segundo post-scriptum no Caso Wagner:

Mas nada pode, no principal, curar a música do principal, da fatalidade de ser expressão da contradição fisiológica - de ser moderna. A melhor instrução, o mais consciencioso treino, a intimidade fundamental, até mesmo o isolamento na companhia dos velhos mestres - tudo isso permanece apenas atenuante, ilusório, falando com mais rigor, por não se ter dentro de si o pressuposto disso: seja a forte raça de um Händel, seja a transbordante animalidade de um Rossini. - Nem todos têm o direito a todo professor: isso vale para épocas inteiras $(W A / C W$, Segundo PósEscrito, KSA 6.49, tradução de PCS).

\section{Dançar nas suas correntes}

Essa "animalidade" de Rossini (que faz eco a sua boa consciência animal evocada no parágrafo 77 de A Gaia ciência) reenvia, como sempre é o caso com Nietzsche, a um estado de civilização determinado por condições fisiológicas. Ora, em Rossini, essa qualidade do corpo consiste, tanto para Nietzsche como para Gast e com a mais rigorosa consequência, no seu ritmo. $\mathrm{O}$ ritmo é o princípio fundamental da organização do tempo, mas também do corpo (o que Nietzsche designa sempre, desde $O$ nascimento da tragédia, pela noção de dança); este é, em realidade, o princípio mesmo do que Nietzsche então chamava de união do dionisíaco e do apolíneo, enquanto que estruturação do devir, transfiguração do caos em cosmo. Das danças orgiásticas dos gregos à estrela dançante do Zaratustra, é a grande saúde como ritmo, como tempo que está sempre em questão. A profunda morbidade da música moderna - e a de Wagner estando na primeira linha - é a falta de ritmo, a desorganização do tempo musical e do corpo: isso provoca, no drama Wagneriano, o aparecimento de personagens histéricos assim como 
Astor, D.

o advento desse monstro oximórico chamado de "melodia infinita". As intermináveis polêmicas em torno da melodia e da harmonia, do poema e da música, do teatro e da ópera etc., são estéreis porque o princípio discriminatório e válido para todos esses pares de oposição é a presença ou a ausência de ritmo, isto é, de hierarquização do tempo e do corpo. Basta escutar alguns compassos de Rossini para se convencer disso e, aliás, ele próprio estava perfeitamente consciente acerca da questão: a música é um "mundo sem limites atraindo e penetrando, indefinito, o qual não pode ser expresso por atos ou palavras. Uma vez que a força de sua expressão lhe vem, não das palavras, mas do ritmo"47(de uma certa maneira, nós temos aqui, numa só frase, o infinito do caos dionisíaco e o ritmo da ordem apolínea). Uma análise musicológica mostraria facilmente que, em realidade, não é a "melodia" que faz a singularidade da escritura rossiniana e, para dizer a verdade, segundo este ponto de vista, Bellini, por exemplo, era mais inspirado. A maneira como toda melodia sumária, em Rossini, é penetrada pelo ritmo (aquele da língua italiana, aquele das coloraturas dividindo todos os valores longos, aquele das células repetidas até à hipnose) procede de uma organização do tempo musical extremamente potente e impositiva (o que chamaram às vezes de uma "mecânica" rossiniana). Essa imposição, muito exigente para o intérprete do ponto de vista técnico, só pode ser transfigurada e tornada inaparente por meio de um igual domínio e liberdade (termos quase sinônimos para Nietzsche) que a antiga escola de canto italiana nomeava morbidezza: essa graça descontraída, o sentimento de facilidade, que é o mandamento supremo do belo canto, deve transparecer até nas passagens mais difíceis. Alguma coisa que lembra inevitavelmente o que Nietzsche chamava "Dançar acorrentado", "acrescentar uma nova coação, impô-la a si mesmos e graciosamente vencê-la: de tal modo que a coação e vitória fossem notadas e admiradas" (WS/AS 140, KSA 2.612).

47 ZANOLINI, A. «Una passeggiata con G. Rossini ”. In : ROGNONI, L. Gioacchino Rossini, (1836), p. 379. 
Esta "Liberdade em correntes - uma liberdade principesca" (WS/AS 159, KSA 2.618) é também todo o objeto do admirável parágrafo 84 da Gaia Ciência à propósito "Da origem da poesia":

Mas, sobretudo, desejaram tirar proveito daquela sujeição elementar que o ser humano experimenta ao escutar música: o ritmo é uma coação; ele gera um invencível desejo de aderir, de ceder; não somente os pés, a própria alma segue o compasso [...] Tal como a fórmula é enunciada, literalmente e ritmicamente exata, ela obriga o futuro; mas ela é invenção de Apolo, que, como deus dos ritmos, pode também obrigar as deusas do destino. Resumindo e perguntando: havia, para a antiga e supersticiosa humanidade, algo mais útil que o ritmo? (FW/GC 84, KSA 3.441/42, tradução de PCS).

A aliança de Apolo e Dioniso permanece, reinvestida na capacidade de um corpo e de uma época em conquistar a imposição na liberdade e a liberdade na imposição, aliança que caracteriza a grande saúde. Essa liberdade e essa imposição são também uma conquista do tempo rítmico, de sua pulsação - de sua pulsionalidade. É desta forma que a nossa música sempre é um indício de nossa saúde, um sinal de declínio ou uma promessa de futuro. Não me parece exagerado pensar que Nietzsche, na medida em que vai tomando consciência que a música de Wagner era sem futuro, pôde considerar que Rossini, este último clássico, artista de um tempo volvido, vulgar e supersticioso como todos os italianos, livre e inocente como eles, com um olhar nostálgico voltado ao passado, encarnava um espécime de individualidade soberana - e, por conta disso, uma paradoxal promessa de futuro. Seria preciso continuar com a reflexão e se perguntar por que Rossini não tomou o lugar de Bizet no grande assalto final contra Wagner e contra a doença. Questão de encontro, de gosto, de urgência. O Sul nietzschiano se radicalizava, e a Itália estava ainda próxima demais: atrás da Andaluzia de Carmem, havia ainda o deserto africano (mas não negligenciemos também o tropismo francês do último Nietzsche: quantas vezes, acreditando admirar Bizet elogiando Carmem, ele elogia, 
Astor, D.

de fato, Mérimée?). A felicidade trágica de Carmen era imediata, revoltada, destruidora - no fundo ela era mais moderna. Nietzsche, com Bizet, reorganizava suas forças contra o caos. Seria preciso ter sido menos ameaçado pela doença para gozar mais plenamente da felicidade fugaz de um Rossini, cuja única revolta contra a modernidade foi um silêncio eleático. - Mas não se escreve sem refletir, nesse tratado de medicina filosófica que representa Ecce Homo, essa frase definitiva: "Eu não saberia passar sem Rossini".

\begin{abstract}
This article aims at reflecting on the relationships between Nietzsche and the Italian opera composer Gioachino Antonio Rossini. In order to trace the development of the influence exerted by the musician on the philosopher, the article provides an accurate summary and then carefully considers the texts of Nietzsche in which Rossini is quoted. Along the piece of writing we try to make it clear that although this influence was a growing one, it proved to be decisive within Nietzsche's life experiences. As a secondary theme, the article also raises some ideas about the relationship between Wagner and Rossini.
\end{abstract}

Keywords: Rossini - Wagner - Opera - Music.

\title{
Referências bibliográficas
}

HANSLICK, E. "Rossini (Nekrologie)". In: Die moderne Oper. Kritiken und Studien: Berlin, 1875

HEINE. H. Über die französische Bühne. In: Werke und Briefe. Berlin: H. Kaufmann (Hrsg.), Bd 6, 1962.

HÜBSCHER, A. "Schopenhauer und Wagner". In: Schopenhauer-Jahrbuch 37, 1956.

MICHOTTE, E. Souvenirs personnels. La Visite de Richard Wagner à Rossini. Fischbacher, 1906.

MUSCHTER, C. Musikleben in Basel: ein Führer durch die Vielfalt der Musikinstitutionen des Stadtkantons. GGG: Basel, 1982.

NIETZSCHE, Friedrich. Sämtliche Werke. Kritische Studienausgabe (KSA), 15 vols. (Organizada por Giorgio Colli e Mazzino Montinari), Berlim: Walter de Gruyter \& Co., 1988.

Sämtliche Briefe: Kritische Studienausgabe (KSB), 8 Vols. (Organizada por Giorgio Colli e Mazzino Montinari ). Berlim: Walter de Gruyter \& Co., 1986. 
Rossini, músico do futuro. Nietzsche e Peter Gast na descoberta da grande saúde rossiniana

Briefwechsel: Kritische Gesamtausgabe (KGB). (Organizada por Giorgio Colli e Mazzino Montinari ). Berlim: Walter de Gruyter \& Co., 1975.

. Gai Savoir: Trad. P. Wotling, Paris: Flammarion, 2007.

ROGNONI, L. Gioacchino Rossini, nuova edizione riveduta e aggiornata. Torino: Einaudi, 1977.

SCHIBLI, S. Musikstadt Basel: das Basler Musikleben im 20. Jahrhundert. Buchverlag der Basler Zeitung, 1999.

SCHOPENHAUER, A. Le Monde comme volonté et représentation. Trad. C. Sommer et all, Gallimard, 2009.

Parerga et Paralipomena. Paris: Coda, 2010.

STENDHAL. Rome, Naples et Florence. In: Voyages en Italie. Paris: Gallimard, "Bibliothèque de la Pléiade", 1973.

STENDHAL. Vie de Rossini. Gallimard: Paris, 1992

WAGNER, C. Journal, t. I (1869-1872), notation du 11 février 1872, Gallimard, 1977. . “Oper und Drama”. In: Gesammelte Schriften und Werke. Bde 3 \& 4: Leipzig, 1907. . “Opéra et Drame. In: Oeuvres en prose. Trad. J.G. Prod'homme, t. IV et . Éditions Delagave: Paris, 1910.

Oeuvres en prose. Trad. J.G. Prod'homme, t. XI et . Éditions Delagave: Paris, 1923. . Souvenirs, "Un Souvenir de Rossini. Trad. de C. Benoît, G. Charpentier et Cie, éditeurs, 1884.

WEBER, C.M. von. “Kunstansichten”. In: Ausgewählte Schriften. K. Laux (Hrgs.): Leipzig, 1975.

ZANOLINI, A. «Una passeggiata con G. Rossini, 1836”. In: ROGNONI, L. Gioacchino Rossini.Torino, Einaudi, 1981.

ZANOLINI, A. Gioacchino Rossini, Zanichelli: Bologne, 1875.

Artigo recebido para publicação em 09/06/2016.

Artigo aceito para publicação em 11/08/2016. 